\title{
Issues in conducting cross-cultural research: implementation of an agreed international protocol designed by the WHOQOL Group for the conduct of focus groups eliciting the quality of life of older adults
}

\author{
Graeme Hawthorne • Natasha Davidson • \\ Kathryn Quinn · Farah McCrate · Ines Winkler · \\ Ramona Lucas · Reinhold Kilian · Anita Molzahn \\ Published online: 10 March 2007 \\ (C) Springer Science+Business Media B.V. 2007
}

Erratum to: Qual Life Res (2006) 15: 1257-1270

DOI 10.1007/s11136-006-0062-4

The original article was published with a spelling error in the title.

The online version of the original article can be found at http:// dx.doi.org/10.1007/s11136-006-0062-4

G. Hawthorne $(\bowtie) \cdot$ N. Davidson

Department of Psychiatry, The University of Melbourne,

Parkville, Victoria 3010, Australia

e-mail: graemeeh@unimelb.edu.au

K. Quinn

Department of Psychiatry, Edinburgh University,

Edinburgh, UK

F. McCrate

Department of Psychology, University of Bath, Bath, UK

I. Winkler

Department of Psychiatry, University of Leipzig,

Leipzig, Germany

R. Lucas

Institut Catala de I'Envelliment, Universitat Autonoma de

Barcelona, Barcelona, Spain

R. Kilian

Department of Psychiatry II, University of Ulm, Günzburg, Germany

A. Molzahn

School of Nursing, University of Victoria, Victoria, Canada 